\title{
As sociedades indígenas nos livros didáticos de história: entre avanços, lacunas e desafios
}

\author{
The Indigenous Societies in the Teaching Books \\ of History: Among Progress, Gaps and Challenges
}

Márcia Elisa Teté Ramos*

Marlene Rosa Cainelli**

Sandra Regina Ferreira de Oliveira ${ }^{\star * \star}$

\section{Resumo}

Neste artigo apresentamos os resultados de uma pesquisa que buscou compreender avanços, lacunas e desafios presentes nos livros didáticos de história quanto à temática indígena segundo a avaliação do PNLD 2017, tendo dois temas como base da investigação: os conteúdos apresentados no livro didático do aluno e as orientações para os professores. Também se recuperam algumas análises sobre a temática indígena em livros didáticos desde a década de 1970, na correspondência com os currículos escolares, entendendo que são materiais interdependentes, tendo como principais fontes as fichas de avaliação dos livros. Os resultados indicam que, conforme já anunciado no texto introdutório do Guia do PNLD 2017, a temática em foco é o ponto mais frágil das 14 coleções aprovadas e, apesar da obrigatoriedade insti-

\section{Abstract}

In this article we present the results of a research whose objective was to understand the progresses, shortcomings and challenges of the History textbooks, with regard to the indigenous theme according to the evaluation of the PNLD 2017, with two themes as the basis of the research: student's textbooks and guidelines for teachers. We also recover some analyzes on textbooks since the 1970s on the indigenous theme, in correspondence with the school curricula, considering them as interdependent materials. The main sources were the evaluation form for the textbooks. The results indicate that, as the introductory text of the PNLD 2017 Guide announces, this theme is the weakest point in the 14 approved collections and, despite the obligation established by Law 11645/2008, the

\footnotetext{
** ProfHistória, Universidade Estadual de Maringá (UEM); Programa de Mestrado em História Social, Universidade Estadual de Londrina (UEL), Maringá, PR, Brasil. metramos@uem.br

** Programa de Pós-Graduação em Educação e Programa de Mestrado em História Social, Universidade Estadual de Londrina (UEL), Londrina, PR, Brasil. marlenecainelli@sercomtel. com.br

*** Programa de Pós-Graduação em Educação, Universidade Estadual de Londrina (UEL), Londrina, PR, Brasil. sandraoliveira.uel@gmail.com
} 
tuída por meio da Lei 11.645/2008, ainda persiste um tratamento das sociedades indígenas brasileiras carregado de limitações e silenciamentos.

Palavras-chave: livro didático; PNLD; temática indígena. treatment of aboriginal peoples is still loaded with limitations and silencing. Keywords: textbook; PNLD; Indigenous theme.

\section{MARCAS DO ENSINO SOBRE HISTÓRIA E CULTURA INDÍGENA NO LIVRO DIDÁTICO}

O tratamento que a temática indígena recebe nos livros didáticos requer uma análise de como historicamente esse assunto se transforma em conteúdo a ser ensinado nas escolas para crianças e adolescentes por intermédio do livro didático, mais especificamente para escolas de sujeitos não indígenas. Falamos, portanto, do ensino sobre um Outro que há séculos é silenciado ou mal interpretado nas narrativas elaboradas sobre o Brasil e os brasileiros. Consideramos que tal (in)compreensão sobre a temática foi e continua sendo empregada para que as lógicas de apropriação e exploração das terras indígenas possam ser legitimadas ou não.

Para analisar o que ensinamos nas escolas sobre os povos indígenas, temos de assumir que, embora um bom caminho tenha sido percorrido nas últimas décadas, tratamos desse assunto a partir dos ditames de uma escola que se recusa a assumir que o ensino de temas complexos e sensíveis passa também por repensar a lógica disciplinar que impera nos documentos curriculares e que, sendo assim, vai reverberar nos materiais didáticos. "As teorias e as disciplinas estão demasiado ocupadas consigo mesmas para poderem responder às questões que o nosso tempo lhes coloca" (Santos; Meneses, 2010, p. 532). A primeira versão da Base Nacional Curricular Comum (BNCC) de História, que assumia uma seleção de conteúdos com ampla abordagem sobre as sociedades indígenas, foi duramente criticada por parte da comunidade acadêmica que clamava pela manutenção de conteúdos clássicos da história geral ocidental. É múltiplo o universo do que poderíamos e/ou gostaríamos de ensinar nas escolas sobre quem somos e o que fazemos como sociedade humana e, por isso, a composição de uma proposta curricular é sempre campo de disputas, na 
medida em que no currículo escolar se apresentam os saberes considerados válidos para serem ensinados (Goodson, 1990).

No ano de 2015, em meio aos debates sobre a proposta da BNCC disponibilizada para consulta pública, Ronaldo Vainfas classificou o documento no jornal O Globo como uma "aberração" por enfatizar “a História do Brasil como o alicerce a partir do qual tais conhecimentos serão construídos ao longo da educação básica", e finalizou afirmando que ele "incentiva ódios raciais e valores terceiro-mundistas superados. Estimula a ignorância, ao colocar a História ocidental como periférica, na realidade como vilã” (Vainfas, 2015). A polêmica envolveu também opiniões e discussões então dispostas em jornais de grande circulação, ${ }^{1}$ assim como em blogs e websites de especialistas e de associações (como é o caso da posição da Anpuh). ${ }^{2}$ Retomamos essa contenda por entendermos que currículo escolar e livro didático têm relação intrínseca, e que questionar o currículo é questionar a organização dos conteúdos nos livros didáticos.

Neste artigo, desenvolvemos nossa argumentação considerando como os indígenas são apresentados como temática a ser discutida em algumas legislações, como nos Parâmetros Curriculares Nacionais do Ensino Fundamental 2, na medida em que o PNLD 2017 se refere a esse nível de ensino, mirando uma discussão sobre multiculturalismo. Discorremos a seguir sobre as legislações referentes à História e Cultura Indígena, observando que a legislação curricular incide diretamente na elaboração do livro didático. Por isso mesmo, recuperamos também alguns estudos já realizados sobre a abordagem dos povos indígenas no livro didático, considerando o antes e o depois das sanções das leis que regulam a obrigatoriedade dessa discussão na escola básica. Por fim, analisamos 14 fichas consolidadas do processo de avaliação do PNLD 2017, centrando a discussão sobre a forma como a temática indígena é tratada no Manual do Professor e no Livro do Aluno. Concluímos assinalando pontos negativos (problemáticas e persistências) e pontos positivos (avanços e possibilidades) encontrados nas avaliações sobre a temática indígena.

\section{CURRÍ́culos E SEUS DESDOBRAMENTOS NO LIVRO DIDÁTICO}

Os Parâmetros Curriculares Nacionais (PCNs) produzidos em meados da década de 1990 não tinham propriamente um foco na história e cultura 
indígena (nem na história e cultura africana e afro-brasileira), mas fundamentavam-se nas discussões da época sobre multiculturalismo, apresentado como "pluralidade cultural" nos Temas Transversais. Peter McLaren é um dos autores que, naquele momento, pensavam o multiculturalismo dividindo-o em algumas tipologias. O multiculturalismo conservador defenderia o projeto de se construir uma cultura comum, em que os grupos étnicos são reduzidos a “acréscimos" em relação à cultura dominante (McLaren, 1997, p. 115). O próprio conservadorismo seria um conjunto instável de diversos grupos, como nos Estados Unidos, por exemplo, em que os monoculturalistas reagiram até mesmo contra a ideia de "colaboração" de outros grupos para a formação cultural, sob o pretexto de que se deveria preservar e fortalecer sua suposta essência, a pureza e o prestígio da cultura "americana". De acordo com Carlos Alberto Torres, os monoculturalistas lamentam o fato de que os professores teriam tomado uma posição adversária aos padrões americanos por causa da discussão sobre multiculturalismo, e que os livros didáticos de história estariam cada vez mais dominados pelos igualitários radicais (Torres, 2001, p. 219). Consideramos que esse tipo de concepção monoculturalista vem ocupando espaço cada vez maior na História Pública, inclusive no Brasil.

O multiculturalismo humanista liberal reconheceria a igualdade intelectual-cognitiva entre etnias e grupos, entendendo que somente por intermédio de reformas que melhorassem as condições de vida dessa população seria possível torná-la competitiva economicamente no modelo social vigente (McLaren, 1997, p. 119). Já a tendência do multiculturalismo liberal mais progressista consistiria em essencializar as diferenças culturais (existiria um modo de ser exclusivamente feminino, uma identidade negra integrada e assim por diante), desprezando o fato de que elas são construídas historicamente e que existem, por assim dizer, “diferenças dentro das diferenças" (McLaren, 1997, p. 120).

Quanto ao multiculturalismo crítico, Peter McLaren compreende que as representações de raça, classe e gênero, por exemplo, são resultado das lutas sociais mais amplas sobre significações. Não se deveria enfatizar somente o jogo textual, os eufemismos, mas colocar em questão as relações de poder envolvidas na construção histórica das diferenças e desigualdades, desnaturalizando-as, de forma a oportunizar resistências (McLaren, 1997, p. 123).

Embora os PCNs alertem que a discriminação deve ser vista não apenas no âmbito comportamental e individual, mas também nas relações sociais, o 
que prevalece no documento é a noção de que o que discrimina são "os gestos, comportamentos e palavras” (Brasil, 1998, p. 137). Em outro ponto do documento percebemos seu enfoque culturalista: "os conhecimentos sociológicos permitem uma discussão acurada de como as diferenças étnicas, culturais e regionais não podem ser reduzidas à dimensão socioeconômica das classes sociais" (Brasil, 1998, p. 131). Entendemos que se as diferenças não se reduzem às questões de classes sociais, mas também não podem ser vistas como deslocadas destas, então as etnias, as culturas consideradas diferentes/minorias, nunca são as mais poderosas economicamente.

Nos PCNs, a pluralidade cultural estaria relacionada aos conteúdos escolares que possibilitem aos alunos compreender, respeitar e valorizar a diversidade cultural e a convivência solidária em uma sociedade democrática (Brasil, 1998, p. 147). Porém, não havia o tratamento da especificidade da questão indígena, pois focalizava-se a diversidade, pluralidade, com um enfoque culturalista, genérico e superficial. Os PCNs prescreviam reconhecer e valorizar o índio, o branco (imigrantes europeus) e o negro (Brasil, 1998, p. 130), como se as três etnias fossem blocos monolíticos, internamente integrados. Por isso mesmo parecem denegar a dinamicidade, os choques, conflitos e as transformações pelas quais os grupos produzem suas identidades, que jamais são unas, mas híbridas, contraditórias, transitórias e em constante construção.

A abordagem pertinente sobre a questão indígena deveria partir da ideia de que existe uma unidade (multiculturalismo) pautada na diversidade (especificidades). Ao mesmo tempo que devemos nos reconhecer sob a égide da igualdade, a diversidade dentro da unidade significa que da mesma forma precisamos nos reconhecer e nos respeitar como grupos com características diferenciadas. Isso implica que o multiculturalismo crítico como pauta abrangente e a afirmação das diferenças étnicas, de gênero, de orientação sexual e religiosa, entre outras, são de urgência social (Candau, 2012). No caso da história e cultura indígena, a bibliografia pesquisada e as fichas de consolidação da avaliação do PNLD nos remetem ao que se chama "pensamento abissal". Parece haver ainda um abismo dividido por uma linha simbólica entre a realidade social de dois universos: o do não indígena e o do indígena. A divisão é tão forte que o "outro lado da linha" desaparece, torna-se invisível, inexistente: "A característica fundamental do pensamento abissal é a impossibilidade da copresença dos dois lados da linha" (Santos; Menezes, 2010, p. 32). 
Diante de várias associações e movimentos que procuraram (e procuram) inserir a história e cultura negra no currículo, em 2003 efetivou-se a Lei 10.639, que versa sobre a obrigatoriedade do ensino da história e cultura afro-brasileira e africana. Cinco anos depois contempla-se também a história e cultura indígena, por meio da Lei 11.645 de 2008, a qual estabelece as diretrizes e bases da educação nacional no sentido de reformulação curricular da educação básica, envolvendo todas as disciplinas do ensino fundamental e médio, sob a obrigatoriedade da temática "História e cultura afro-brasileira e indígena".

Certamente a Lei 11.645 é relevante para reelaborar currículos e livros didáticos. Lei é um preceito, uma norma produzida para estabelecer as regras que devem ser seguidas, controlar os comportamentos e ações dos indivíduos de acordo com os princípios de uma sociedade. Se antes havia a multiculturalismo como "parâmetro" ou um dos componentes dos Temas Transversais - o que de certa forma colocava a discussão, como a própria nomenclatura sugere, na transversalidade curricular -, agora os currículos acadêmicos e escolares, bem como os livros didáticos devem ser reestruturados no sentido de encaixar efetivamente tais leis. Estas advêm do Estado, mas é bom lembrar que uma série de movimentos sociais procuraram inserir suas demandas no currículo escolar. A elaboração do currículo é um processo permeado pelo conflito, pela negociação e pela (re)interpretação, conforme interesses divergentes sobre qual projeto social é considerado legítimo, quais conteúdos e métodos são válidos para cada disciplina escolar (Goodson, 1995, p. 53). Nessa relação de forças entre o Estado e diferentes grupos sociais, vale retomar a noção de Goodson sobre legislação curricular, pois esse autor diferencia o currículo prescrito, o oficial, do currículo ativo, o que se constitui nas salas de aula como prática ou (re)criação (Goodson, 1991, p. 8). A forma como os currículos prescritos pelos órgãos oficiais é traduzida no livro didático constitui o currículo editado (Escolano, 2006), o que pode interferir no currículo ativo, pois na prática, o professor tende a usar muito mais o livro didático do que propriamente a legislação curricular. Por isso, nos editais do PNLD é critério obrigatório a incorporação de certas leis no livro didático.

A Lei $11.645^{3}$ alterou o artigo 26-A da Lei 9.934/96. Como é próprio da natureza de uma lei, as considerações não são práticas, mas referem-se à implementação curricular, e não se tem em vista uma reflexão sobre o assunto. Porém, podemos perceber nas entrelinhas: os diversos aspectos da cultura que 
caracterizam a formação da população brasileira nos remetem a objetivos vagos e dispersos. Ao propor resgatar as contribuições dos afrodescendentes e indígenas, percebe-se o multiculturalismo liberal-conservador de que Peter McLaren nos falava e que estava presente nos PCNs, quando as etnias eram vistas como acréscimos à cultura matriz e não se justificava por que conteúdos históricos devem ser vistos em especial nas áreas da educação artística e de literatura. Não que essas disciplinas não sejam importantes para explorar a temática, mas novamente podemos ver essa proposição como restritiva, ao associar a história da África e dos africanos e a dos povos indígenas ao terreno das manifestações artísticas.

De forma mais consistente e explicativa, as Diretrizes Curriculares Nacionais para a Educação das Relações Étnico-Raciais e para o Ensino de História e Cultura Afro-Brasileira e Africana procuram se fundamentar no multiculturalismo crítico. Contudo, a tradição curricular na disciplina da História, ou seja, a história cronológica, quadripartite e eurocêntrica, é empecilho nessa empreitada. A cultura europeia como central para organização dos conteúdos históricos termina por subentender a subalternidade ou complementaridade das outras sociedades. Esta ordem das coisas termina por desdobrar-se nos livros didáticos. Contudo, acreditamos que as leis e diretrizes citadas são marcos na mudança da forma como a temática indígena é tratada no livro didático de história.

O livro didático de história vem sendo visto como "objeto de suspeição" (Munakata, 2009) desde a década de 1970. O livro As Belas Mentiras: a ideologia subjacente nos livros didáticos, de Maria de Lourdes Chagas Deiró Nosella, procura mostrar que os livros didáticos: não levam em conta os conflitos entre indígenas e não indígenas; oscilam entre considerar os indígenas de forma romântica e enxergá-los como terríveis e cruéis; ou ainda, ora exaltam o indígena, ora o ridicularizam; "teriam sido sempre colaboradores de seus conquistadores e exploradores portugueses"; finalizando, as crianças indígenas são muito felizes e têm uma relação igualitária/harmoniosa com as crianças não indígenas; os indígenas vivem nas florestas e não nas reservas (Nosella, 1981, p. 191-197).

Naquele contexto histórico, os livros didáticos certamente adequavam-se ao currículo proposto pelos governos militares, que falava de identidade nacional e amor à Pátria, sem mencionar o indígena de forma evidente. Maria 
Cristina Floriano Bigeli em tese de doutorado de 2018 faz um inventário dos autores que tratam do livro didático de história, em específico sobre a temática indígena. Mauro Willian Barbosa de Almeida, em 1987, analisa livros da década de 1970 e destaca a forma como os bandeirantes são vistos como grandes heróis, pois teriam promovido a expansão do território nacional. Não se fala do custo humano ao terem apresado ou mesmo assassinado os indígenas (Almeida, 1987, p. 49). Esse autor também considera que: apenas os Tupi são lembrados nos livros didáticos de Estudos Sociais e Educação Moral e Cívica, em detrimento de vários outros povos indígenas; o indígena "bom”, colaborador do branco, nos deixa importante herança cultural, ou seja, é como se ele não estivesse presente na sociedade (Almeida, 1987, p. 69-70). Nayane Rodrigues Cordeiro Mariano realizou uma pesquisa considerando as imagens dos livros didáticos e concluiu que o modelo conservador do Brasil do Oitocentos permanece em muitos materiais do século XX: "são passadas concepções fragmentadas, folclorizadas e cômodas, existem muitos silêncios em volta do assunto e esses manuais permanecem distantes da realidade histórica" (Mariano, 2006, p. 95).

Quanto à década de 1980, a antropóloga Norma Telles ressalta o exotismo com o qual é vista a cultura indígena (Telles, 1987). Bigeli, ao tratar da análise dessa autora, nos mostra que prevalece naquele momento a ideia de deficit da cultura indígena: "os indígenas não falam, não possuem, não são: não têm moral, não sabem trabalhar, não sabem construir a moradia” (Bigeli, 2018, p. 33). Na década de 1990, as críticas quanto às abordagens sobre o indígena no livro didático não diferem muito das realizadas anteriormente. A cultura indígena é vista pelo seu suposto deficit, pelo exotismo, pela sua "herança cultural" - supondo que o indígena é uma figura do passado -, e a diversidade dos povos indígenas é ignorada (Grupioni, 1996; Mota; Rodrigues, 1999; Bigeli, 2018, p. 34-35). Lúcio Tadeu Mota e Isabel Rodrigues, embora nos façam ver as permanências quanto ao modo como se considera o indígena no livro didático, apontavam naquele momento certa mudança "quando os índios passaram a ter uma atuação política mais visível nos níveis nacional e internacional, a utilizarem mecanismos jurídicos para fazer seus direitos, principalmente os relacionados à terra, serem respeitados" (Mota; Rodrigues, 1999, p. 42). Se antes falava-se de "contribuição" ou "colaboração" do indígena (multiculturalismo conservador), esses autores mostram que já existe a preocupação em 
indicar os conhecimentos próprios dos indígenas, como astronomia, venenos de pesca, venenos de caça, tapiragem, borracha, alimentação (Mota; Rodrigues, 1999, p. 51), ou seja, rompem-se timidamente as permanências, considerando o indígena como protagonista da história. Antes, Luis Donisete Benzi Grupioni argumentava que os próprios indígenas teriam se dado conta da problemática, e professores indígenas realizaram encontros para discutir a forma como os livros didáticos tratavam de sua história (Grupioni, 1996, p. 425).

Adentrando os anos 2000, Leandro Magalhães entende que os livros didáticos de história ainda privilegiavam a perspectiva dos colonizadores. Naquele momento, os autores que analisavam livros didáticos de história passaram a perceber que os textos não se atualizavam segundo uma nova historiografia sobre o indígena que, como vimos, se constituíra ainda na década de 1970. Também Gobbi, em 2006, considera que o livro didático ainda traz estereotipias, preconceitos, ideias evolucionistas, visões eurocêntricas. Já Macêdo, em 2009, traz um enfoque diferenciado, pois procura perceber as apropriações que alunos e professores fazem do livro didático: como o livro traz generalizações e estereótipos, os agentes escolares respondem sobre o indígena da mesma forma.

Todos esses autores nos apontam a permanência de problemáticas postas nos livros didáticos de história. Podemos resumir os questionamentos em relação ao livro didático (História, Estudos Sociais e Educação Moral e Cívica) em alguns eixos inter-relacionados: tratam do indígena apenas no passado; tratam do indígena apenas na condição de subalternidade e de aculturação; tratam do indígena sob a égide do estereótipo, às vezes de forma pejorativa, às vezes romântica; não consideram a diversidade de povos indígenas, tratando-os de forma homogênea; trazem a ideia de mostrar a colaboração do indígena apenas em relação a algumas manifestações culturais (língua e comida) e partem do eurocentrismo, da ideia desenvolvimentista, civilizatória ou evolucionista.

Sobre os livros didáticos publicados após a Lei 11.645/08, Maria de Fátima Barbosa da Silva analisa em 2012 uma coleção aprovada pelo PNLD de 2011. Começamos a perceber o impacto dessa lei, pois a autora entende que houve certos avanços, interdependentes com a atualização historiográfica: participação dos indígenas em outros momentos da história que não fossem apenas ligados à colonização, ao passado; problematização quanto às disputas sobre as terras indígenas; desconstrução de estereótipos, como da "preguiça" 
indígena (Bigeli, 2018, p. 48). Gleice Keli Barbosa Souza (2015) e Felipe Nunes Nobre (2017) também veem que o livro didático de história veio se tornando mais satisfatório do ponto de vista da atualização historiográfica, em especial, sob a avalição do PNLD, mas argumentam que ainda há preconceitos em relação ao indígena.

Percebemos que esses autores julgam positivamente o livro didático, embora vários outros o considerem problemático, por apresentarem uma visão eurocêntrica, preconceituosa, generalizante (Palhares, 2012; Liz, 2014; Souza, 2016). A pesquisa de Isabelle Cristine de Almeida Souza (2016) é interessante no sentido de relacionar as ideias dos livros didáticos com uma revista de consumo que é material de grande circulação. A autora aproxima as ideias do livro didático mais com um material midiático do que com a historiografia, demonstrando que determinadas concepções discutíveis sobre o indígena integram a chamada História Pública. Em outras palavras, livro didático e materiais midiáticos terminam por configurar o que se pensa sobre os indígenas em variadas esferas sociais de ações e interações, e o que se pensa ainda é baseado em estereótipos, preconceito e eurocentrismo.

Sintetizamos os questionamentos desses autores em relação ao livro didático de história em alguns eixos inter-relacionados, Avanços: atualização conforme a historiografia; positivação do PNLD para avaliação e "controle" do livro didático; indígenas vistos na atualidade também, não só no passado, e desconstrução de estereótipos. Ainda sobre os problemas: estereótipo, generalização e preconceito; não consideram a diversidade de povos indígenas, tratando-os de forma homogênea, e partem do eurocentrismo, da ideia desenvolvimentista, civilizatória ou evolucionista.

Uma chance de promover mais abordagens atualizadas e que permitem a desconstrução de preconceitos em relação à história e cultura indígena poderia ser a Base Nacional Comum Curricular (BNCC) em sua primeira versão (2015), relativa à História. Essa versão, se implementada, permitiria reelaborar e modificar de fato o modo como o indígena é apresentado no livro didático de história, pois toma como ponto de partida para o processo didático-pedagógico o rompimento com a história eurocêntrica em prol de uma história pertinente para a realidade do aluno, ou seja, a História do Brasil. Assim, o multiculturalismo crítico de fato integra o conhecimento histórico por meio 
do currículo e se aplica à legislação referente à inclusão da História da África, dos afrodescendentes e história e culturas indígenas.

Como dissemos na introdução deste artigo, a BNCC enfrentou diversas críticas, principalmente em relação ao fato de se partir da História do Brasil, da história e das culturas negra e indígena. A ideia era considerar a realidade próxima, o mundo do aluno, contudo a BNCC não esclarecia o referencial teórico no qual se embasava, e por isso mesmo não esclarecia a relação entre História do Brasil e a questão global. A grande mídia e muitos historiadores entenderam que começar da História do Brasil fazia desaparecer ou seria menosprezar a História Antiga e Medieval. Segundo Arnaldo Pinto Junior, João Batista Gonçalves Bueno e Maria de Fátima Guimarães, essas críticas se movem tendo como eixo a retórica da perda (Pinto Junior; Bueno; Guimarães, 2016, p. 65), ou seja, a ideia de que o currículo escolar de história ficaria empobrecido com a suposta retirada de alguns conteúdos. Argumentam os autores que nessa retórica da perda estaria embutida a repetição do modelo consolidado da história quadripartite, bem como a ignorância relativa aos avanços epistemológicos na área do ensino de história (Pinto Junior; Bueno; Guimarães, 2016, p. 66). Os autores também consideram que a BNCC propunha uma alteração no lugar de produção das narrativas históricas, rompendo com uma hierarquia na composição das narrativas, em que aquelas consideradas menos válidas correspondem às que tiveram um passado colonial (Pinto Junior; Bueno; Guimarães, 2016, p. 74).

Quanto à terceira e última versão da BNCC, o indígena volta a ser considerado de forma vaga, pautada no multiculturalismo conservador. Aponta-se a necessidade de incluir "temas obrigatórios definidos pela legislação vigente, tais como a história da África e das culturas afro-brasileira e indígena, [que] devem ultrapassar a dimensão puramente retórica e permitir que se defenda o estudo dessas populações como artífices da própria história do Brasil” (Brasil, 2016, p. 351). Embora aponte o fato de que os currículos vinham até então priorizando uma visão eurocêntrica que deveria ser rompida (Brasil, 2016, p. 351), na composição curricular não há espaço para que se efetive esse rompimento. $\mathrm{O}$ indígena aparecerá como ponto de discussão em um componente curricular em cada ano, mesmo assim junto a outras etnias (Brasil, 2016, p. 353), e surge certa inovação apenas ao se propor, no $9^{\circ}$ ano, "Identificar e 
relacionar as demandas indígenas como forma de contestação ao modelo desenvolvimentista da ditadura" (Brasil, 2016, p. 381).

\section{A TEMÁTICA INDÍGENA NOS LIVROS DIDÁTICOS APROVADOS NO PNLD 2017}

É fato que as discussões fomentadas pelos envolvidos durante o processo de avaliação suscitam importantes subsídios para pensar os materiais didáticos, no entanto, a rotina desse processo, focada na análise dos livros sob a égide de um edital específico, impede uma análise formal e sistematizada. Por isso, ao término do processo avaliativo do PNLD 2017 retomamos as fichas consolidadas das 14 coleções, para comparar como os avaliadores julgam a temática indígena no livro didático de história. Outro fator que justifica a realização desse estudo é que a tipologia de avaliação das coleções e, em decorrência, a forma como o resultado é publicado no Guia do $\mathrm{PNLD}^{4}$ impedem a construção de análises comparativas do conteúdo dos livros, dificultando um olhar horizontal para as coleções no que tange à necessidade de encontrar lacunas, problemas ou equívocos.

No concernente à abordagem sobre os povos indígenas no livro didático localizam-se três orientações no Edital PNLD 2017 (Brasil, 2017, p. 50), todas situadas no Anexo III, intitulado "Princípios e critérios para a avaliação de coleções didáticas". No item 2.1.1, que regulamenta o "Respeito à legislação, às diretrizes e às normas oficiais relativas ao ensino fundamental", assevera-se que "serão excluídas as coleções que não obedecerem aos seguintes estatutos: 2. Lei de Diretrizes e Bases da Educação Nacional, com as respectivas alterações introduzidas pelas Leis 10.639/2003, 11.274/2006, 11.525/2007 e 11.645/2008”. Como vimos, a Lei 11.645/2008 reporta à história e cultura africana, afrodescendente e indígena.

No item 2.1, "Critérios eliminatórios comuns a todas as áreas", são estabelecidos os seguintes parâmetros a serem observados no processo de avaliação das obras:

6. promover positivamente a imagem de afrodescendentes e descendentes das etnias indígenas brasileiras, considerando sua participação em diferentes trabalhos, profissões e espaços de poder; 
7. promover positivamente a cultura afro-brasileira e dos povos indígenas brasileiros, dando visibilidade aos seus valores, tradições, organizações e saberes sociocientíficos, considerando seus direitos e sua participação em diferentes processos históricos que marcaram a construção do Brasil, valorizando as diferenças culturais em nossa sociedade multicultural. (Brasil, 2017, p. 49)

Ao estabelecer os "Critérios específicos eliminatórios para o componente curricular História”, na parte específica sobre o Manual do Professor, estabelece esta normativa: "4. orienta o professor sobre as possibilidades oferecidas pela coleção didática para a implantação do ensino de História da África, da cultura afro-brasileira e da História das nações indígenas" (Brasil, 2017, p. 59). $\mathrm{Na}$ ficha de avaliação utilizada no processo de 2017, elaborada com base no edital, esses quesitos foram organizados em três questões, sendo:

Questão 8 (Manual do Professor): Orienta o professor sobre as possibilidades oferecidas para a abordagem significativa e pertinente do ensino de história e cultura africana, afro-brasileira e dos povos indígenas em estrita observância às Leis $10.639 / 03$ e $11.645 / 08$. (p. 125)

Questão 29 (Formação Cidadã): Cumpre a Lei no 11.645/2008 - "Altera a Lei no 9.394, de 20 de dezembro de 1996, modificada pela Lei no 10.639, de 9 de janeiro de 2003, que estabelece as diretrizes e bases da educação nacional, para incluir no currículo oficial da rede de ensino a obrigatoriedade da temática "História e Cultura Afro-Brasileira e Indígena”. (p. 131)

Questão 31 (Formação Cidadã): A obra cumpre a Lei n. 11.645, de 10 de março de 2008 (história e cultura afro-brasileira e indígena). Nesta questão atenha-se ao que diz respeito à história e à cultura indígena. Lei no 11.645/2008 - "Altera a Lei $\mathrm{n}^{\circ}$ 9.394, de 20 de dezembro de 1996, modificada pela Lei no 10.639, de 9 de janeiro de 2003, que estabelece as diretrizes e bases da educação nacional, para incluir no currículo oficial da rede de ensino a obrigatoriedade da temática "História e Cultura Afro-Brasileira e Indígena”. (p. 133)

Durante o processo de treinamento dos avaliadores a Lei 11.645/08 é apresentada com detalhamentos e exemplificações sobre o tratamento dos povos indígenas nos livros didáticos, em relação tanto aos problemas identificados como às abordagens consideradas exemplares no cumprimento da Lei. Trata-se também do Manual do Professor, abordando as tipologias de material para 
subsidiá-lo no trato do tema (textos complementares, sugestões de leituras, filmes etc.) e o desdobramento da temática no livro do aluno.

Neste texto, vamos considerar as questões 8 (Manual do Professor) e 31 (Formação Cidadã). Para responder a essas questões o avaliador deve, após a leitura de toda a coleção, indicar as partes do livro nas quais a temática indígena é abordada, registrando essas passagens na ficha e analisando, qualitativamente, se o conteúdo assevera uma abordagem concernente ao estabelecido por Lei. Toda essa operação é realizada individualmente por dois avaliadores, no formato duplo cego e com a total descaracterização das obras. Em um segundo momento, quando as fichas individuais foram finalizadas e entregues aos coordenadores adjuntos, os avaliadores entraram em contato e elaboraram conjuntamente a ficha consolidada. O resultado é que se tem um cabedal robusto de informações que podem basear as mais variadas análises sobre o conteúdo dos manuais didáticos. ${ }^{5}$ Tendo a ficha consolidada, em uma próxima etapa do processo serão elaborados os pareceres de aprovação ou exclusão das obras.

\section{Resultados E ANÁlise SOBRE A TEMÁtICA INDÍGENA NOS LIVROS DE HistóRIA DO PNLD 2017}

Aliando-nos aos autores já citados neste artigo, que há décadas dedicam-se a compreender e divulgar como a temática indígena é tratada nos livros, efetuamos a análise das respostas dos avaliadores às questões 8 e 31 da Ficha Consolidada e organizamos a apresentação dos resultados em três blocos, a saber: detalhamento sobre os conteúdos que mais constam nos manuais; quais são e como são as orientações dispostas para o professor; e quais avanços e lacunas são anunciados nas fichas consolidadas.

A leitura comparativa das fichas consolidadas permite acompanhar os conteúdos selecionados pelos autores das obras didáticas para abordarem a temática indígena, conforme se pode observar em alguns trechos aqui transcritos:

(...) a História e a cultura dos povos indígenas são abordadas em suas lutas pela ocupação e pelo reconhecimento de terras e de outras questões sociais que se desdobram dessas lutas tradicionais;

(...) trata a História indígena ao abordar a América pré-colombiana, os índios hoje, 
os indígenas na América do Norte, o patrimônio linguístico dos indígenas brasileiros, a colonização espanhola na América, a conquista e a colonização da América e alguns movimentos de resistência indígena;

(...) as populações indígenas são tratadas com ênfase na história desses povos na América, particularmente, no Brasil, revelando elementos culturais e as suas lutas;

(...) a temática indígena é abordada tanto em relação aos povos indígenas no Brasil como de outras regiões da América, destacando a diversidade cultural existente entre esses povos, sua escravização pelos europeus, sua resistência e suas lutas atuais pelo direito à terra e à preservação de suas tradições.

Conforme apontado pelos avaliadores, a forma como a cultura indígena é referendada nas obras e os desdobramentos de tais abordagens, no tocante à compreensão desses povos na atualidade, são identificados em algumas passagens nas quais destaca-se a diversidade, e em outras, a resistência, como retratam estes trechos:

(...) há imagens de crianças indígenas numa referência às diferentes experiências com o tempo, conforme o grupo social, e menções aos calendários dos povos indígenas, assim como aos mitos de origem;

(...) no tocante à História e cultura indígena, (...), preocupa-se, na obra, em discutir a diversidade de grupos e de experiências, por meio de textos e de imagens que destacam a presença dos indígenas na História, priorizando suas ações de resistência, a participação em movimentos de emancipação e a diversidade de suas práticas culturais;

(...) a coleção inclui as temáticas (...) das culturas indígenas em todos os volumes, com discussões sobre sua história, memória e cultura integrada em dinâmicas históricas mais amplas no Brasil e no mundo;

(...) quanto aos indígenas, em particular, é desmitificada a imagem que o posiciona apenas no passado. A abordagem valoriza realidades do passado e situações atuais, o que contribui para a construção de atitudes e de valores cidadãos, no que se refere à valorização, à aceitação e ao respeito ao outro. Os conteúdos apresentados contribuem para a formação de uma nova consciência social com relação aos afrodescendentes e aos povos indígenas, problematizando a condição histórica e social desses atores;

(...) salienta-se a presença histórica no passado e no presente e a diversidade étnica dospovosindígenasem todososvolumes. Apontam-seaslutas por reconhecimento, 
por inclusão e por autonomia dos povos indígenas na comunidade nacional, realçando o debate pelas terras e o rico patrimônio imaterial, com valor reconhecido pela Unesco;

(...) a história dos povos indígenas está representada nos diversos volumes da coleção, desde os períodos pré-históricos, mas com menor ênfase na atualidade; investe em textos e imagens que destacam aspectos positivos, evidenciando as cores e a beleza, levando à compreensão de que são cultural e politicamente exitosos e respeitados em suas sociedades;

(...) na coleção, as situações de preconceito contra os povos indígenas são debatidas em sua historicidade, o que possibilita ações de questionamento e repúdio a tais práticas. Essas questões são tratadas nos textos e também são exploradas nas atividades e nas imagens, o que pode favorecer a reflexão sobre a afirmação dos direitos desses sujeitos;

(...) imagens e textos são utilizados visando positivar a imagem tanto do afro-brasileiro quanto do indígena na História do Brasil, auxiliando, também, na problematização da questão étnico-racial;

(...) ressalva-se que tais conteúdos colaboram parcialmente para o estudo de temáticas que abordem as problemáticas em torno das relações étnico-raciais quanto ao enfrentamento do preconceito e do racismo experienciados pelos povos indígenas na contemporaneidade.

No que se refere ao recorte aqui estabelecido, identificamos que as 14 coleções, ainda que apresentem diferenças significativas quanto ao nível de aprofundamento na abordagem da temática indígena, têm semelhanças quanto à seleção dos conteúdos. Na maioria das vezes o indígena é tratado nos capítulos que abordam a sociedade colonial brasileira, normalmente no livro de $6^{\circ}$ ano. É retomado em meio ao conteúdo que trata da questão da escravização de pessoas ao longo do século XVII e no processo das Entradas e Bandeiras, e claramente como adendo, como complemento aos temas principais, ao tratar de assuntos relacionados ao tempo presente.

Em algumas coleções a temática indígena é tratada de modo mais extenso, em outras de forma bem mais pontual, ainda que, como já dito, com base em conteúdos semelhantes. De forma geral, nas coleções com abordagens mais extensas as escolhas recaem sobre assuntos já consagrados na historiografia e se complementam com questões relacionadas à cidadania e ao convívio social, 
como o reconhecimento das diferenças, a valorização e o respeito à identidade pessoal e à diversidade cultural. Constatamos que em todas as coleções os conflitos e lutas de resistência dos indígenas no passado e no presente brasileiro estão apresentados de forma secundária, assim como a temática do genocídio indígena, a difícil situação de alguns grupos indígenas na atualidade e as problemáticas envolvendo a distribuição de terras. Tais temáticas, quando presentes, são tratadas de forma tangenciada em textos complementares e/ou em indicações de pesquisas complementares.

Em linhas gerais, concluímos que os conteúdos sobre a temática indígena que estão mais presentes nas coleções são: primeiras civilizações a ocupar o continente americano; presença indígena na formação da nação brasileira; estudo dos povos indígenas da América, destacando os tupi-guarani, os maias, os incas e os astecas; utilização da mão de obra indígena nos primeiros anos da colonização do Brasil pelos portugueses; cristianização dos indígenas nas missões jesuíticas; bandeirantismo; referências a grupos indígenas nos Estados Unidos da América; anúncio sobre a diversidade cultural dos povos indígenas, mas sem avançar no tratamento dessa diversidade.

De forma pontual, em algumas coleções encontram-se conteúdos como: participação política de indígenas no Brasil atual; situação dos povos indígenas no Brasil de hoje; investigação sobre lendas indígenas; sociedades indígenas do Alto Xingu; "ressurgimento" dos indígenas no Brasil, ou seja, o que se chama de virada demográfica na atualidade; o Quarup, uma festa no Xingu; trilhas indígenas que vão da região Sul/Sudeste do Brasil até o Peru; participação indígena na Guerra do Paraguai e educação indígena.

Também buscamos identificar quais são as orientações dispostas para o professor sobre a abordagem da temática indígena em sala de aula. Em grande parte das fichas analisadas, menciona-se que há referência na coleção ao fato de o currículo escolar ter negligenciado o estudo dos povos indígenas durante muito tempo e que, a partir da Lei 11.645/08 essa situação vai se alterando. Em apenas um dos 14 Manuais explicitam-se algumas indicações para que o professor discuta a temática indígena com os alunos, sobretudo quanto às ausências e aos silenciamentos referentes a esses povos.

Em todos os manuais destinados aos professores constam textos autorais e artigos acadêmicos que contemplam informações historiográficas e metodológicas que podem auxiliar o professor no desenvolvimento, junto aos 
estudantes, de abordagens sobre a temática indígena. Agrupando o que se destaca nas fichas consolidadas, concluímos que os manuais apresentam: um conjunto de indicações bibliográficas, algumas acompanhas de sinopse, sobre a temática indígena; orientações para o professor sobre o estudo da história e cultura indígena, alertando para a construção histórica de preconceitos e estereótipos relacionados às sociedades indígenas; indicações de livros, sites e filmes sobre a temática indígena; textos, alguns atualizados e outros nem tanto, sobre a temática indígena e fontes diversificadas que auxiliam uma abordagem ampla e plural da historicidade dos povos indígenas. No entanto, constam poucas orientações acerca das barreiras a serem superadas quanto ao tema.

No estudo sobre a temática indígena nos livros didáticos aprovados no PNLD 2017 analisamos também os avanços e lacunas anunciados nas fichas consolidadas e traçamos um quadro sobre alguns desafios a serem enfrentados.

Com relação às lacunas identificamos que as coleções cumprem, em diferentes escalas, as normativas nacionais curriculares para o ensino de história dos anos finais do Ensino Fundamental sobre o ensino da história e cultura indígena. Entretanto, esse trabalho é assimétrico entre as coleções e mesmo entre os volumes de uma mesma coleção. As principais ausências identificadas são: a organização da narrativa principal é cronológica e eurocêntrica, de modo que os temas da legislação são abordados sempre em referência à história europeia; a temática aparece de forma limitada, sem ressaltar a presença dos povos indígenas na atualidade como algo relevante nem aprofundar os conflitos ou problemáticas em relação à questão indígena no Brasil; as contribuições desses povos nas áreas social, econômica e política praticamente estão ausentes das coleções; a abordagem sobre os conteúdos referentes a essa temática ocorre em determinados períodos da história (de forma geral os indígenas são apresentados ainda ligados à colonização), apresentando pouco das suas problemáticas atuais; não se realiza uma reflexão mais aprofundada sobre a problemática histórica que originou a criação da Lei 11.645/08; não se observa um investimento amplo no que se refere à temática do preconceito étnico-racial em todas as coleções; não há a superação de algumas interpretações recorrentes sobre a história dos povos indígenas no Brasil, tais como a descrição do índio genérico ou padrão sem apontar a multiplicidade de povos que viveram e vivem em território brasileiro, com diferenciações em seus modos de vida; há poucos relatos de indígenas sobre o processo de colonização e defesa da memória de 
suas culturas. Os povos indígenas são trabalhados sem adentrar sua historicidade e as lutas travadas pela manutenção de suas terras após a chegada dos portugueses ao Brasil, até a contemporaneidade; faltam referências aos povos indígenas que vivem isolados em periferias das cidades e em aldeias urbanas, concedendo enfoque apenas aos povos que vivem em aldeias ou áreas rurais.

Com relação aos avanços, ainda que por força de lei, a temática indígena está presente em todas as coleções aprovadas, o que corrobora a valorização da diversidade cultural no Brasil. Destacamos os seguintes pontos mais valorativos: a história indígena é apresentada nas coleções com a preocupação de desfazer estereótipos e de salientar a luta dos indígenas na atualidade, ainda que tais abordagens apresentem lacunas importantes, como se viu no item anterior; há tentativas de valorização dos indígenas como protagonistas dos processos históricos, entretanto, esse protagonismo é tratado de forma bem pontual; há correlações entre o passado e o presente, o que possibilita em algumas coleções abordar esses sujeitos para além do contexto colonial; há, em algumas coleções, indicações de discussões historiográficas recentes sobre a temática indígena.

\section{CONSIDERAÇÕES FINAIS}

As deficiências mais apontadas no Manual do Professor foram: não discute ou discute de forma superficial a temática sobre os indígenas e não traz subsídios suficientes quanto ao tema. Porém, algumas obras não oferecem problemas, e outras apresentam problemas que poderiam ter sido já superados, como: tratar de forma homogênea os povos indígenas e se referir e eles predominantemente no período da colonização. Quanto aos pontos positivos, vemos que o Manual do Professor cumpre as leis quanto à temática indígena, e alguns exemplares trazem subsídios suficientes e pertinentes para que o professor possa trabalhar em sala.

Sobre o critério de Formação Cidadã, presente no Livro do Aluno, temos a maior incidência de pontos negativos nestes itens: a questão indígena é relegada ao período da colonização; o indígena ainda não é visto como protagonista, como sujeito que resiste e luta, ou ainda, a disputa pelo território indígena não é considerada e o indígena não é visto na atualidade. Ainda se apresenta o problema de ver os povos indígenas como grupo homogêneo, e alguns 
termos ou conceitos são vistos de forma equivocada, como "índio" (o correto é indígena, já que índio é o habitante da Índia), "tribo" (refere-se aos povos nômades apenas) e "canibalismo" (não é visto como um ritual). Contudo, alguns avanços podem ser visualizados: mostram as lutas, as resistências, o protagonismo indígena no passado e no presente, e já não trazem os indígenas como grupo homogêneo, nem como sujeito presente apenas no período da colonização.

Comparando com as análises realizadas sobre os livros didáticos desde a década de 1970 até os tempos atuais, as fichas consolidadas referentes à avaliação do PNLD 2017 nos mostram que muito se tem avançado em relação à temática indígena. Procura-se muito mais a desconstrução dos preconceitos em geral e a produção de valores e ações baseados no respeito e compreensão das diferenças, demonstrando uma concepção pautada no multiculturalismo crítico. A legislação que regula a obrigatoriedade do tratamento da história e cultura indígena parece surtir efeitos positivos nos livros didáticos de história, destacando as especificidades históricas e culturais étnicas, mas deparamos com algumas permanências que revelam um "pensamento abissal". A ideia de "contribuição" harmoniosa das matrizes étnicas, sem que se percebam os conflitos, as disputas e resistências, sem que se perceba que indígenas têm história, conhecimento e cultura próprios e importantes para a formação brasileira; termos ou conceitos desatualizados, que mostram falta de esclarecimento, de fundamentação científica sobre o indígena; o silenciamento da questão indígena na atualidade, como se ela fosse plausível apenas ao se falar do Brasil colonial.

Os desafios são muitos e, decerto, as leis e diretrizes aqui comentadas servem ao propósito de fazer avançar ainda mais a discussão. Uma base curricular nos moldes da primeira versão da BNCC-História poderia constituir uma reformulação de fato nos livros didáticos, permitindo que os alunos significassem sua própria história como partícipes de uma sociedade multicultural e, ao mesmo tempo, pautada na riqueza da diversidade.

\section{REFERÊNCIAS}

ALMEIDA, Mauro Willian B. de. O racismo nos livros didáticos. In: SILVA, Aracy L. de (org.). A questão indígena na sala de aula: subsídios para professores de $1^{\circ}$ e $2^{\circ}$ graus. São Paulo: Brasiliense, 1987. p. 13-71. 
BIGELI, Maria Cristina F. Ensino de história e cultura indígena: os discursos do Currículo São Paulo Faz Escola (2014-2017) e dos docentes de História. 2018. Tese (Doutorado em Educação) - Universidade Estadual Paulista "Júlio de Mesquita Filho" (Unesp). Assis, 2018.

CANDAU, Vera Maria F. Diferenças culturais, interculturalidade e educação em direitos humanos. Educação e Sociedade, Campinas, v. 33, n. 118, p. 235-250, jan./mar. 2012.

ESCOLANO, Agustín. Currículum editado y sociedad del conocimiento: texto, multimedialidad y cultura de la escuela. Valencia: Tirant lo Blanch, 2006.

GOBBI, Izabel. A temática indígena e a diversidade cultural nos livros didáticos de história: uma análise nos livros recomendados pelo Programa Nacional do Livro Didático. 2006. Dissertação (Mestrado em Ciências Sociais) - Universidade Federal de São Carlos (UFSCar). São Carlos, 2006.

GOODSON, Ivor. Tornando-se uma matéria acadêmica: padrões de explicação e evolução. Trad. Tomaz T. da Silva. Teoria \& Educação, Porto Alegre, n. 2, p. 230-254, 1990.

GOODSON, Ivor. La construcción social del currículum: posibilidades y ámbitos de investigación de la historia del currículum. Revista de Educación, Madrid, n. 295, p. 7-37, 1991.

GOODSON, Ivor. Historia del Currículum: la construcción social de las disciplinas escolares. Barcelona: Pomares-Corredor, 1995.

GRUPIONI, Luis Donisete B. Imagens contraditórias e fragmentadas: sobre o lugar dos índios no livro didático. Revista Brasileira de Estudos Pedagógicos, Brasília, v. 77, n. 186, p. 422-437, maio/ago. 1996.

LIZ, Marcela de. A representação dos povos originários brasileiros nos livros didáticos de história do Ensino Fundamental. 2014. Trabalho de Conclusão de Curso (História) - Universidade Federal do Pampa (Unipampa). Jaguarão, RS, 2014.

MACÊDO, Celênia de Souto. O índio como o outro: o desafio de construir uma identidade positiva a partir dos livros didáticos. 2009. Dissertação (Mestrado em Ciências Sociais) - Programa de Pós-Graduação em Ciências Sociais, Centro de Humanidades, Universidade Federal de Campina Grande (UFCG). Campina Grande, PB, 2009.

MAGALHÃES, Leandro Henrique. O índio brasileiro no livro didático. História \& Ensino, Londrina, v. 6, p. 73-89, 2000.

MARIANO, Nayane R. C. A representação sobre os índios nos livros didáticos de História do Brasil. 2006. Dissertação (Mestrado em Educação) - Universidade Federal da Paraíba (UFPB). João Pessoa, 2006.

MCLAREN, Peter. Multiculturalismo crítico. Trad. Bebel O. Schaefer. São Paulo: Cortez, 1997. 
MOTA, Lúcio Tadeu; RODRIGUES, Isabel Cristina. A questão indígena no livro didático “Toda História”. História \& Ensino, Londrina, v. 5, p. 41-59, out. 1999.

NOBRE, Felipe Nunes. Nos meandros do (re)conhecimento: a temática indígena em livros didáticos de História no contexto de implementação da Lei 11.645/08 (20082014). 2017. Dissertação (Mestrado de Educação) - Universidade Federal de Pelotas (Ufpel). Pelotas, RS, 2017.

NOSELLA, Maria de Lourdes C. D. As belas mentiras: a ideologia subjacente aos livros didáticos. 4. ed. São Paulo: Moraes, 1981.

PALHARES, Leonardo M. Entre o verdadeiro histórico e a imaginação criadora: história e cultura dos povos indígenas em livros didáticos de História. 2012. Dissertação (Mestrado em Educação) - Faculdade de Educação, Universidade Federal de Minas Gerais (UFMG). Belo Horizonte, 2012.

PINTO JUNIOR, Arnaldo; BUENO, João Batista G.; GUIMARÃES, Maria de Fátima. A BNCC em pauta: quando vamos estudar nossa História? In: MOLINA, Ana Heloisa; FERREIRA, Carlos Augusto L. (org.). Entre textos e contextos: caminhos do Ensino de História. Curitiba: CRV, 2016.

SANTOS, Boaventura de Sousa; MENESES, Maria Paula. Da colonialidade à descolonialidade. (Parte 1). In: SANTOS, Boaventura de Sousa; MENESES, Maria Paula (org.). Epistemologias do Sul. São Paulo: Cortez, 2010.

SILVA, Maria de Fátima B. da. Livro didático de História: representações do índio e contribuições para a alteridade. Revista História Hoje, São Paulo: Anpuh, v. 1, n. 2, p. 151-168, 2012.

SOUZA, Gleice Keli B. "Os esquecidos da História” e a Lei 11.645/08: continuidades ou rupturas? Uma análise sobre a representação dos povos indígenas do Brasil em livros didáticos de História. 2015. Dissertação (Mestrado Acadêmico em Educação) - Universidade Estadual de Feira de Santana (UEFS). Feira de Santana, BA, 2015.

SOUZA, Isabelle Cristine de A. Povos indígenas do Brasil: representações dos povos indígenas na coleção didática Araribá História e reportagens da revista Veja (20082014) 2016. Dissertação (Mestrado em História) - Universidade Federal da Paraíba (UFPB). João Pessoa, 2016.

TELLES, Norma. A imagem do índio no livro didático: equivocada, enganadora. In: SILVA, Aracy L. da (org.). A questão indígena na sala de aula: subsídios para professores de $1^{\circ}$ e $2^{\circ}$ graus. São Paulo: Brasiliense, 1987. p. 73-99.

VAINFAS, Ronaldo. Nova face do autoritarismo. O Globo, Rio de Janeiro, 5 dez. 2015. Disponível em: http://oglobo.globo.com/opiniao/nova-face-do-autoritarismo $-18225777$. 


\section{Documentos:}

BRASIL. Diretrizes Curriculares Nacionais para a Educação das Relações Étnico-Raciais e para o Ensino de História e Cultura Afro-Brasileira e Africana. 2004. Disponível em: http://portal.mec.gov.br/cne/arquivos/pdf/res012004.pdf.

BRASIL. Edital PNLD 2017. Disponível em: https://www.fnde.gov.br/programas/programas-do-livro/consultas/editais-programas-livro/item/6228-edital-pnld-2017.

BRASIL. Lei no 11.645/2008. Disponível em: http://www.prograd.ufu.br/legislacoes/ lei-no-11645-de-10-marco-de-2008-historia-e-cultura-afro-brasileira-e-indigena.

BRASIL. Parâmetros Curriculares Nacionais: terceiro e quarto ciclos: apresentação dos temas transversais. Brasília: MEC/SEF, 1998.

Pareceres (disponíveis em http://mtete7.wixsite.com/lemh2016/pareceres): Flávia Eloisa Caimi, Luis Fernando Cerri, Renilson Rosa Ribeiro, Marcelo de Souza Magalhães e Martha Campos Abreu.

\section{NOTAS}

${ }^{1}$ Algumas críticas: "História sem Tempo", por Demétrio Magnoli e Elaine Senise Barbosa (Gazeta do Povo, 8 out. 2015); "Ensino de História no Brasil em xeque", por Rosana Félix (Gazeta do Povo, 18 out. 2015); "Mudanças no ensino de história são prejudiciais, diz professor da Unicamp", com Pedro Paulo Funari (Folha de S. Paulo, 23 out. 2015); "Proposta de ministério que altera ensino de história causa reações", com Sabine Righetti (Folha de S. Paulo, 22 nov. 2015); "Proposta do MEC para ensino de história mata a temporalidade", com Demétrio Magnoli e Elaine Senise Barbosa (Folha de S. Paulo, 8 nov. 2015).

${ }^{2}$ Disponível em: http://site.anpuh.org/index.php/2015-01-20-00-01-55/noticias2/noticias-destaque/item/3352-manifestacao-publica-da-anpuh-sobre-a-base-nacional-comum -curricular.

${ }^{3}$ Disponível em: http://www2.camara.leg.br/legin/fed/lei/2008/lei-11645-10-marco-2008-572787-publicacaooriginal-96087-pl.html.

${ }^{4} \mathrm{O}$ Guia se caracteriza em resenhas que têm como definição uma análise crítica e informativa sobre uma obra, mas realizada de forma breve.

${ }^{5}$ Consulta franqueada ao público com o resguardo do sigilo sobre autoria, editoria e títulos.

Artigo recebido em 23 de novembro de 2018. Aprovado em 22 de fevereiro de 2019. 